\title{
Pseudo-Sciatica Due to Pelvic Tumor. Case Presentation
}

\author{
Luis Crescencio Bretón Espinosa1, Lázaro Martin Martínez Estupiñan², Leonardo Martínez \\ Aparicio $^{3}$, Ramón Delgado Carro ${ }^{4}$, Claribel Plain Pazos ${ }^{5 *}$ and Leonardo Domínguez Plain ${ }^{6}$ \\ ${ }^{1}$ I Degree Specialist in Orthopedics and Traumatology, Assistant Professor, Provincial General University Hospital "Mártires del
} 9 de Abril", Sagua la Grande, Villa Clara, Cuba

${ }^{2}$ Doctor in Medical Sciences, II Degree Specialist in Orthopeadics and Traumatology, Full Professor, Provincial General University Hospital "Mártires del 9 de Abril" Sagua la Grande, Cuba

${ }^{3} 3^{\text {rd }}$ year resident of Orthopedics and Traumatology, Provincial General University Hospital "Mártires del 9 de Abril" Sagua la Grande, Cuba

${ }^{4}$ I Degree Specialist in Orthopedics and Traumatology Provincial General University Provincial General University Hospital "Mártires del 9 de Abril" Sagua la Grande, Cuba

${ }^{5}$ Specialist of I and II Degree in Comprehensive General Medicine, Faculty of Medical Sciences of Sagua la Grande, Cuba

${ }^{6}$ Resident of $3^{\text {rd }}$ year of Orthopedics and Traumatology, Provincial General University Hospital "Mártires del 9 de Abril”, Sagua la Grande, Villa Clara, Cuba

*Corresponding author: Claribel Plain Pazos, Faculty of Medical Sciences of Sagua la Grande, Villa Clara, Cuba

\section{ARTICLE INFO}

Received: 慧April 19, 2021

Published: 慧 May 04, 2021

Citation: Luis Crescencio BE, Lázaro Martin ME, Leonardo MA, Ramón Delgado C, Claribel PP, et al., Pseudo-Sciatica Due to Pelvic Tumor. Case Presentation. Biomed J Sci \& Tech Res 35(4)-2021. BJSTR. MS.ID.005720.

\section{ABSTRACT}

Lumbo-sciatic pain is a symptom caused by a wide variety of processes that can be degenerative, inflammatory, infectious or tumor in nature. We present a patient with confusing clinical characteristics where the delay in diagnosis produces serious consequences. The presence of alarm signs, which can translate systemic diseases, and the need to start a study protocol on the subject are discussed.

Keywords: Pseudosciatica; Pelvic Tumor; Sciatica

\section{Introduction}

Lumbo-sciatic pain is a symptom caused by a wide variety of processes that can be degenerative, inflammatory, infectious or tumor in nature. Low back pain is a very common presenting symptom in the primary care clinic. Between 70 and $80 \%$ of the world's adult population has had an episode of low back pain at least once in their life, of these only $10-12 \%$ will have concomitant sciatica $[1,2]$. This pain syndrome is among the first causes of physical limitation in individuals under 45 years of age $[1,3,4]$ although sciatica will rarely be found in patients under 20 years of age, since the predominant age at which it is suffered is around
40 years [5]. Pseudo-sciatica is a term diagnosis sometimes used to describe sciatic nerve symptoms that are not due to typical spinal sources [1].

Depending on the etiology, low back pain can be classified as nonspecific or specific. If there is a known reason, this will be considered specific, which comprise around $20 \%$, the main causes being herniated discs or osteoporotic fractures, and 5\% due to a serious problem such as tumor processes or aortic aneurysm. On the other hand, those cases where the etiology is unknown will be named as nonspecific low back pain, constituting $85 \%$ of the cases 
[6]. Low back pain is not a diagnosis, it is a symptom that describes the presence of pain in the lumbar vertebral or paravertebral region without referring to the structures causing the process. The poor anatomical and clinical correlation of patients with low back pain is known [7]. Tumor lesions are frequent; in the diagnosis of SOMA lesions, confusing them due to their clinical presentation is also frequent, which complicates early diagnosis and therefore the correct therapy. This presentation is intended to address a rare case interpreted as sacrumlumbosciatica at first and later diagnosed as a pelvic tumor.

\section{Case Presentation}

A 56-year-old female patient works as a vector inspector in a polyclinic in our city. It begins with pain at the level of the unilateral gluteal region, with numbness of the lower limb up to the foot on that side, no traumatic antecedents are collected, nor important previous efforts for the lumbosacral spine. She is evaluated in the primary health care consultation, she was interpreted as sciatica and treatment with B complex vitamins was applied, evolves for approximately 50 to 60 days, does not improve and is referred to the specialized orthopedic consultation. On December 24, 2020 she is evaluated in the orthopedic specialty consultation of the Polyclinic, she finds the following questioning and physical examination:

a) No pain relief with the previously indicated therapy.

b) Does not refer relationship or increased pain to the efforts of coughing, sneezing or defecation.

c) Absence of antalgic scoliosis or pain on flexion of the normal lumbar spine.

d) Normal gait, without giving up. - Sezé sign in negative L4L5 and L5-S1 lumbar spaces.

e) Pain on deep palpation in the gluteal area on the side of pain, in relation to the sciatic nerve.
Neurological exam:

f) Lassegue painful at 70 degrees, approximately.

g) Decreased sensitivity of the knee to the foot, of the affected limb, without defining a specific place.

h) Toe and heel gait of the normal foot on both sides.

i) Normal Patellar and Achilles reflex.

j) Dorsiflexion of the ankle and first joint of both feet, equally normal, were verified.

Sciatic nerve blocks are indicated, review of vitamin therapy, rest from work and a new re-consultation.

Evaluated again 3 weeks later, she refers to partial improvement, since the paresthesias of the knee down improved, although she maintained the non-intense pain in the gluteal region mentioned above on deep palpation; Upon being questioned more deeply, she states that she had lost several pounds of weight, but she could not specify the amount or the time. She was indicated a plain radiograph in anteroposterior view of the bony pelvis and radiography of the lumbosacral spine in anteroposterior and lateral views, in the first osteolytic lesions appear at the level of the ischium and branches of the pelvis (Figure 1). A computerized axial tomography was performed, where the defects of the ischium and bone pelvis are much better observed, as well as bone destruction lesions, possibly metastatic at the level of the sacrum and adjacent fifth lumbar vertebra (Figure 2). In addition, she was also evaluated by the General Surgery service, since several cervical lymphadenopathies were found on physical examination; The patient refused to undergo a biopsy or other studies and three weeks later she died in her home. The cause of death could not be determined due to family refusals to carry out the autopsy.

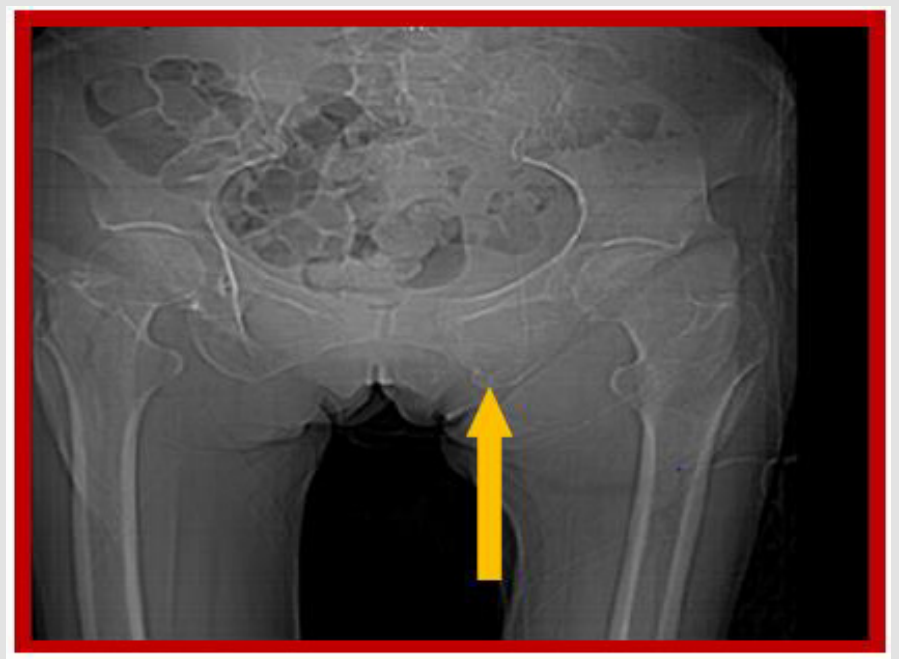

Figure 1: Radiological image showing a destructive bone lesion at the level of the ischio-pubic branch. 


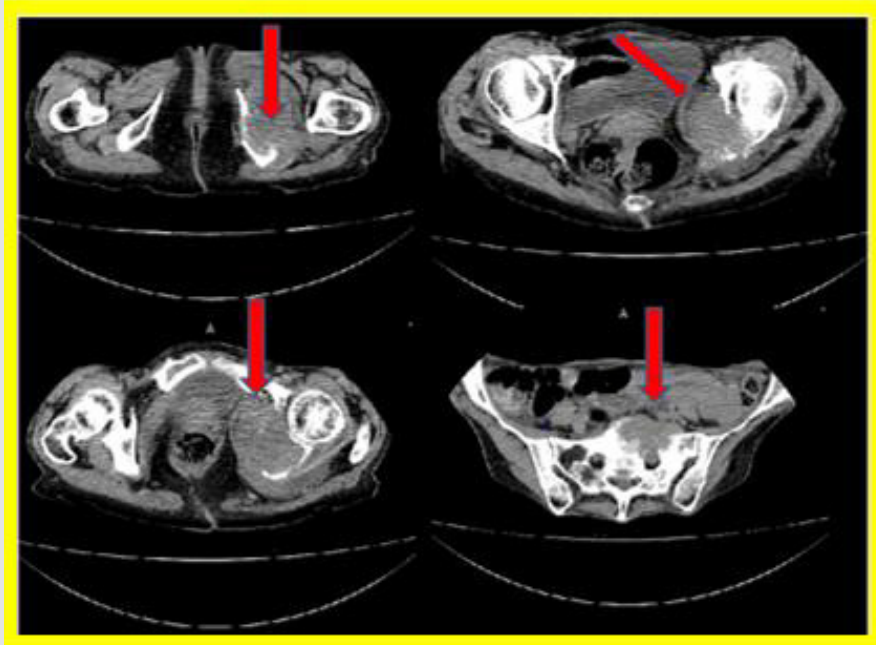

Figure 2: Serial tomographic images showing a destructive tumor lesion at the level of the bony pelvis and the sacrum.

\section{Discussion}

Low back pain is a very frequent syndrome in the general population, which occurs in approximately $9.4 \%$ of the global population, it is a common condition, which nevertheless requires interdisciplinary and complex management. When combined with abdominal-pelvic pain, it is a complex entity, sometimes difficult to diagnose, which requires a thorough analysis to determine its causes and the most appropriate treatment. It involves various viscera, so frequently the approach must be multidisciplinary and sometimes requires rapid action since the life of the patient is at stake [6]. The presence of warning signs can translate into systemic diseases and the need to start a study protocol. Among them the following: [7]

Age from 20 years to over 50 years.

a) Existence of a report of direct or indirect, spectacular or strong injury.

b) Pain in the rib cage or abdominal region.

c) Unexplained weight loss.

d) Rise in body temperature.

e) Progressive neurological clinic.

f) Progression of disability accompanied by pain.

g) Personal history or family history with cancer problems.

h) Bone malformations of the spine.

i) Drug addiction, low immune defenses or Human Immunodeficiency Virus (HIV) infections.

j) Extended and repeated use of steroids.

k) Continuous and delicate lumbar flexion impossibility.

l) Pain that does not decrease with rest.
In this particular case, the patient was 56 years old, she had no previous history of trauma or suffering from pain in the lumbar region, the pain began incidiously and did not improve with treatment and rest. The pelvis is a common site of primary malignant tumors, it represents between 5 and $15 \%$ of all malignant primary bone tumors, etiologically chondrosarcomas and osteosarcomas are more frequent. The characteristics of the pelvic bones (large volume, extension, closeness of the abdominal visors), late diagnosis and the complexity of the resection and reconstruction techniques worsens the prognoses, the periacetabular area represents a region of significant decrease in the physical capacity of patients [8].

The bony pelvis is one of the places in the skeleton where we can most frequently find tumor lesions. However, these lesions usually come from tumors of visceral origin (carcinoma metastases) or blood (leukemias, lymphomas, myelomas). Infiltration of the bony wall of the pelvis by visceral tumors located in the pelvic cavity is also relatively frequent. When a mass is located in a limb, it is more easily detectable than when it is located in the pelvis. The tumor in the pelvis has more "room" to grow without being noticed by the patient. The clinical picture is often superimposable with that of lumbar degenerative pathology, which is one of the most frequent reasons for consultation for the orthopedic surgeon [9]. In the case presented, the presence of the primary tumor could not be identified, as the patient died earlier to locate it and it was not possible to perform an autopsy due to the family's refusal.

Bone metastases represent the most common type of malignant bone tumor. The incidence varies depending on the means used for diagnosis. Thus, when we use clinical and radiological data, $15 \%$ of patients with carcinoma present with bone metastases, a figure that increases to $30 \%$ if the data come from autopsies. The vertebral column, especially the dorso-lumbar and sacral spine, the pelvic bones, are the most common locations for bone 
metastases [7]. In the case presented, it was possible to identify the lesions at the level of the bone pelvis corresponding to bone metastases. In Brazil it is estimated that between 62 and $90 \%$ of patients with bone neoplasms have pain, other authors comment on the presence of hematuria [9]. De Mattos Brito Oliveira VE, Batista Torres K, Carneiro Leite JJ [10] report that giant cell tumors are rare, they occur between 8 and $10 \%$ of benign primary bone tumors. Its prevalence is higher after skeletal maturity (third and fourth decades of life), with a low predilection for women.

These tumors mainly affect the tibiae and, less frequently, the vertebrae, the pelvis, and the sacrum. They can be associated with pseudo-tumor conditions, malignant tumors, metastases (10\%), mainly to the lung. The main symptom is pain (54.4\%). In the case presented, the patient was female, she did not present hematuria and the affected bones were those of the pelvis and ischium. Jorge Hokama [11] in a study of 2951 patients with a diagnosis of pseudo-sciatica reports that the incidence of unusual sciatica is reported in $3.2 \%$, in $87.2 \%$ of the patients, the clinical examination led to the presumptive diagnosis of unusual sciatica. The time elapsed between the onset of symptoms and the final diagnosis was highly variable, averaging 15.5 months. The average age was 55.3 years with a predominance of women $(56.4 \%)$, the incidence according to the etiology was tumor in $24.46 \%$ of the total number of patients seen. In the case presented, the clinical and radiological examination led to the diagnosis of bone metastasis, despite not having found the primary tumor.

The authors consider that the initial evaluation of patients with radicular lumbar pain syndrome should include a questioning and physical examination aimed at guiding and establishing the diagnosis. The questioning should be aimed at determining aspects such as the onset of pain, location, type and characteristics, factors that increase and decrease it, previous trauma to the thoracolumbar region and sciatica, psychosocial stress factors at home or at work, ergonomic factors, repeated movements and overload, whether or not it is the first painful picture and the presence of warning signs. The tumor cause must always be taken into account. An early diagnosis can help save lives.

\section{References}

1. Thiyagarajan S, Prabhu C (2017) Pseudo Sciatica-It's the Condition we really Treat Better than Medicine. J Nov Physiother 7(1): 327-328.

2. Jiménez Ávila JM, Rubio Flores EN, González Cisneros AC (2018) Directrices en la aplicación de la guía de práctica clínica en la lumbalgia. Cirugía y Cirujanos 86(1): 29-37.

3. Morla Guaman SM (2019) Tratamiento de ciatalgia mediante la implementación de la neurodinamia (Bachelor'sthesis, Quito: UCE).

4. Merino Orbegoso PA (2020) Sobrepeso y lumbalgia en personal en actividad complejo hospitalario PNP Luis Nicasio Sáenz 2019.

5. Cordero Fraile V (2019) Efectividad de la neurodinamia respecto al tratamiento convencional de fisioterapia en pacientes adultos con ciatalgia.

6. Alvarado FB (2019) Lumbalgia Crónica, Revista Ciencia y Salud 3(1): ág8.

7. Valero de Bernabé Calle ME (2017) Lumbalgia crónica en la población española. Factores asociados y calidad de vida según la Encuesta Nacional de Salud 2011.

8. San Julián Aranguren M (2003) Sarcomas óseos de la pelvis. Rev Ortop Traumatol 47: 202-209.

9. Salvador Marín J, Izquierdo Plazas L, Ausina Gómez S, López-López C, Castro-Copete MC (2020) Hematuria como primer signo del condrosarcoma de pelvis. Acta Ortopédica Mexicana 34(5): 313-318.

10. De Mattos Brito Oliveira VE, Batista Torres K, Carneiro Leite JJ (2019) Inoperable Sacral Giant Cell Tumor: Therapeutic Options and Pain Control. RevBrasOrtop 54(3): 347-352.

11. Hokama J (2020) Diagnóstico de las ciatalgias y cruralgias de causas no habituales. Rev Asoc Arg Ortop y Traumatol 65(4): 264-274.
ISSN: 2574-1241

DOI: 10.26717/BJSTR.2021.35.005720

Claribel Plain Pazos. Biomed J Sci \& Tech Res

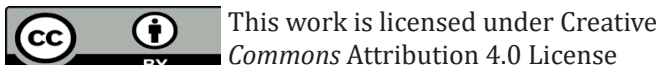

Submission Link: https://biomedres.us/submit-manuscript.php

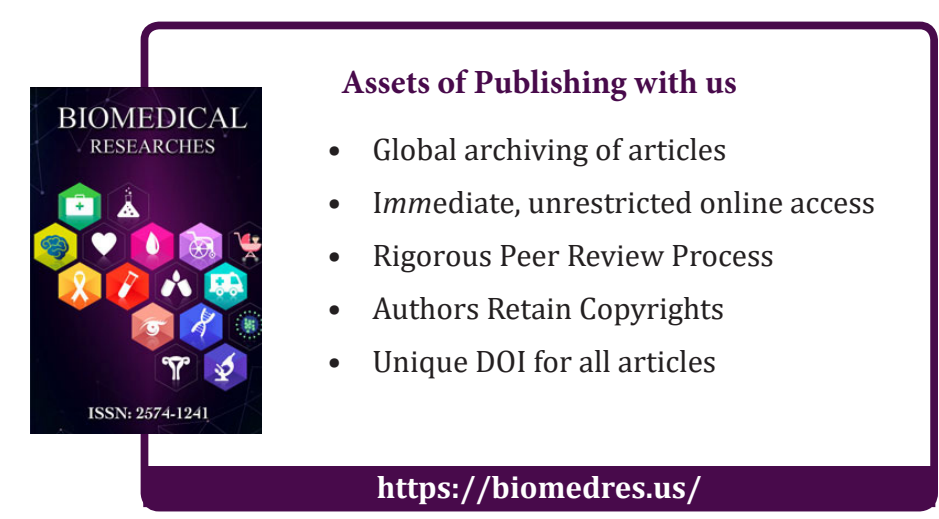

